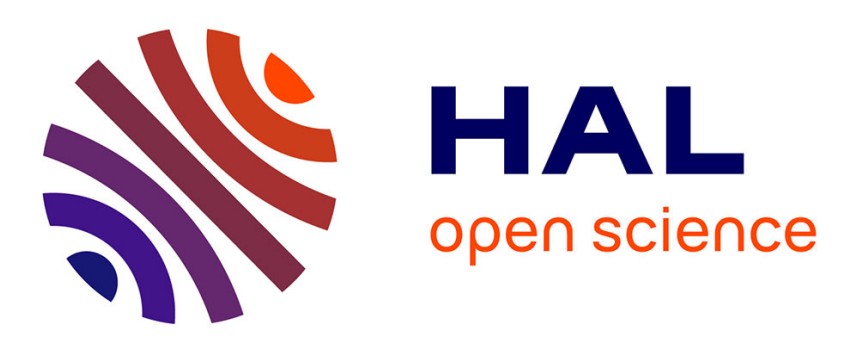

\title{
Characterization of energetic and thermalized sputtered tungsten atoms using tuneable diode-laser induced fluorescence in direct current magnetron discharge
}

\author{
M Desecures, L. de Poucques, J. Bougdira
}

\section{- To cite this version:}

M Desecures, L. de Poucques, J. Bougdira. Characterization of energetic and thermalized sputtered tungsten atoms using tuneable diode-laser induced fluorescence in direct current magnetron discharge. Plasma Sources Science and Technology, 2015, 24 (1), pp.015012. 10.1088/0963-0252/24/1/015012 . hal-02314389

\author{
HAL Id: hal-02314389 \\ https://hal.science/hal-02314389
}

Submitted on 12 Oct 2019

HAL is a multi-disciplinary open access archive for the deposit and dissemination of scientific research documents, whether they are published or not. The documents may come from teaching and research institutions in France or abroad, or from public or private research centers.
L'archive ouverte pluridisciplinaire HAL, est destinée au dépôt et à la diffusion de documents scientifiques de niveau recherche, publiés ou non, émanant des établissements d'enseignement et de recherche français ou étrangers, des laboratoires publics ou privés. 


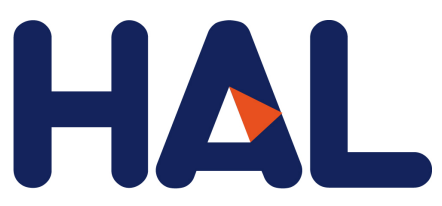

archives-ouvertes

\title{
Characterization of energetic and thermalized sputtered tungsten atoms using tuneable diode-laser induced fluorescence in direct current magnetron discharge
}

\author{
M Desecures, L. de Poucques, J. Bougdira
}

\section{- To cite this version:}

M Desecures, L. de Poucques, J. Bougdira. Characterization of energetic and thermalized sputtered tungsten atoms using tuneable diode-laser induced fluorescence in direct current magnetron discharge. Plasma Sources Science and Technology, IOP Publishing, 2015, 24 (1), pp.015012. 10.1088/09630252/24/1/015012 . hal-02314389

\section{HAL Id: hal-02314389 \\ https://hal.archives-ouvertes.fr/hal-02314389}

Submitted on 12 Oct 2019

HAL is a multi-disciplinary open access archive for the deposit and dissemination of scientific research documents, whether they are published or not. The documents may come from teaching and research institutions in France or abroad, or from public or private research centers.
L'archive ouverte pluridisciplinaire HAL, est destinée au dépôt et à la diffusion de documents scientifiques de niveau recherche, publiés ou non, émanant des établissements d'enseignement et de recherche français ou étrangers, des laboratoires publics ou privés. 


\title{
Characterization of energetic and thermalized sputtered tungsten atoms using tuneable diode-laser induced fluorescence in direct current magnetron discharge
}

\author{
M Desecures $^{1,2}$, L de Poucques ${ }^{1,2}$ and J Bougdira ${ }^{1,2}$ \\ ${ }^{1}$ Université de Lorraine, Institut Jean Lamour UMR 7198, Vandoeuvre-lès-Nancy, F-54506, France \\ ${ }^{2}$ CNRS, Institut Jean Lamour UMR 7198, Vandoeuvre-lès-Nancy, F-54506, France \\ E-mail: mikael.desecures@univ-lorraine.fr
}

Received 19 May 2014, revised 27 September 2014

Accepted for publication 21 October 2014

Published 1 December 2014

\begin{abstract}
In this study a tuneable diode-laser induced fluorescence (TD-LIF) technique $\left(\lambda_{0}=407.4358 \mathrm{~nm}\right)$ is used to determine the atoms' velocity distribution function (AVDF) of energetic and thermalized sputtered tungsten (W) atoms in direct current magnetron discharge. The AVDF is characterized by probing the plasma above the centre of the target racetrack along the magnetron cathode axis in an argon-helium ( $\mathrm{Ar}-\mathrm{He}$ ) mixture.

Quantitative absorption measurements corroborated by deposition on silicon substrates are used to calibrate the TD-LIF relative measurements. Density, flux, temperature, AVDF and the flux velocity distribution function are derived from fitting the TD-LIF signals with four Gaussians (thermalized atoms) and four (energetic atom) functions (Stepanova and Dew 2004 Nucl. Instrum. Methods Phys. Res. B 215 357) taking into account the natural abundance and resonance wavelength shifts of the four main isotopes. Measurements show transport improvement for $\mathrm{W}$ atoms and an increase of the ratio of Ar ions to Ar neutrals with the increase of the percentage of $\mathrm{He}$. All measurements are performed at $0.4 \mathrm{~Pa}$ and $100 \mathrm{~W}$. The mean velocity of energetic $\mathrm{W}$ atoms typically ranges from 1900 to $2200 \mathrm{~m} \mathrm{~s}^{-1}$. The densities of thermalized and energetic atoms are in the same order of magnitude $\left(\sim 10^{9} \mathrm{~cm}^{-3}\right)$ and their corresponding fluxes are several tens of times higher for energetic atoms $\left(\sim 10^{15} \mathrm{~cm}^{-2} \mathrm{~s}^{-1}\right)$.
\end{abstract}

Keywords: tungsten sputtering, atoms energy distribution functions, laser-induced fluorescence, laser absorption spectroscopy

(Some figures may appear in colour only in the online journal)

\section{Introduction}

Sputtered particle sources such as magnetron discharges have been widely used in thin film deposition applications. In order to improve and control film properties, knowledge of the sputtered atoms' velocity distribution function (AVDF) is important. In particular, for a high- $Z$ material with low thermal diffusion such as tungsten (W), the impinging particles' energy is determinant in controlling the mobility of condensing atoms during thin layer growth on the substrate [1], e.g. for WC (hard coating) [2] and $\mathrm{WO}_{3}$ (electrochromic device technology) [3] The low surface mobility of W atoms leads to porous structures with poor properties while, through an increase of the atoms' mobility, dense coatings with good physical properties can 


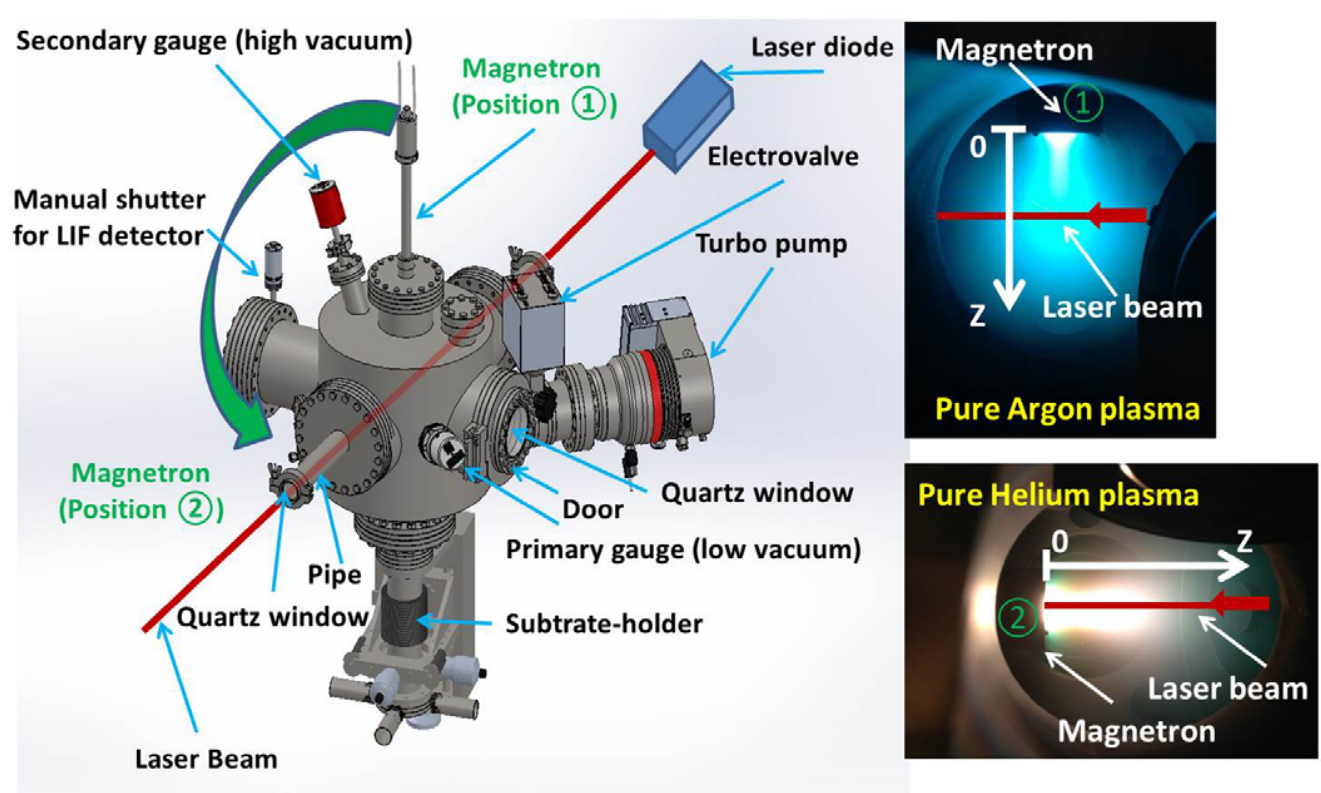

Figure 1. A scheme of the reactor.

be obtained [4]. Moreover, $\mathrm{W}$ is currently considered as a prime candidate for plasma-facing components of the ITER divertor because of its desirable properties [5, 6]. However, physical erosion results in the formation of $\mathrm{W}$ atoms and dust particles which are then subsequently carried into the plasma core inducing a severe degradation of the plasma properties required for the fusion reactions [7]. As the penetration depth into the plasma depends on the energy of the sputtered atoms, it is crucial to obtain experimentally the AVDF of neutral tungsten during the sputtering process. The ITER divertor will interact with $\mathrm{He}$ (a product of fusion reactions) and $\mathrm{Ar}$ (considered as one of the possible coolants). Therefore, the use of an Ar-He gas mixture is of great interest for divertor [8] and deposition studies.

Diagnostics using laser diodes are among the most powerful techniques for studying plasma as they are not intrusive and allow the acquisition of accurate experimental results. Only few studies using such techniques have been performed on sputtered atoms such as aluminum (Al) [9, 10] and titanium (Ti) atoms [11-17]. In this work, new measurements on $\mathrm{W}$ atoms are presented. The tuneable diode-laser induced florescence (TD-LIF) technique is used to determine the AVDF of energetic and thermalized sputtered $\mathrm{W}$ atoms in direct current (dc) magnetron discharges. The AVDF is measured by probing the plasma above the centre of the target racetrack along the cathode magnetron axis in an $\mathrm{Ar}-\mathrm{He}$ gas mixture. Tuneable diode-laser absorption spectroscopy (TDLAS) absolute measurements, corroborated with deposition on silicon substrates, were used to calibrate TD-LIF relative measurements. Density, flux, temperature, AVDF and flux velocity distribution function (FVDF) are determined taking into account the natural abundance and shifted resonance wavelength of the isotopes. This study is focused on the influence of the percentage of helium $(\% \mathrm{He})$ in the $\mathrm{Ar}-\mathrm{He}$ gas mixture, the distance from the target, and on both energetic and thermalized $\mathrm{W}$ sputtered populations.

\section{Experimental apparatus}

\subsection{Reactor}

The experiments were carried out in a conventional dc magnetron sputtering discharge. The reactor illustrated in figure 1 is a cylindrical stainless steel chamber, $35 \mathrm{~cm}$ in height and $30 \mathrm{~cm}$ in diameter. We used a standard planar balanced magnetron cathode which operates with a tungsten target of $50 \mathrm{~mm}$ diameter, $3 \mathrm{~mm}$ thickness and $99.6 \%$ purity. Two positions of the magnetron are possible depending on the laser diagnostic used (detailed in the following subsection). The magnetic field flux density is $100 \mathrm{mT}$ at the centre of the target and lower elsewhere. The cathode is moveable in the direction perpendicular to the target surface to allow one to perform space-resolved measurements along this $z$-axis without modifying the optical arrangement set-up. The chamber is equipped with long cylindrical pipes in order to use optical diagnostic methods and to avoid $\mathrm{W}$ deposition on the windows. The chamber also has two other fused quartz windows, facing each other; through one (the one protected by a manual shutter) light is collected with an optical fibre for TD-LIF measurements. The vacuum system consists of two vacuum pumps. A low vacuum of $0.1 \mathrm{~Pa}$ is reached using a primary vacuum pump and a high vacuum of $7 \times 10^{-5} \mathrm{~Pa}$ is achieved using a secondary turbomolecular pump (VAT). The gas is introduced through Ar and He flowmeters injecting up to $20 \mathrm{sccm}$ and $50 \mathrm{sccm}$, respectively. The measurements are performed with different gas mixtures starting from pure $\mathrm{Ar}$ and then increasing the \% $\mathrm{He}$ in steps of about $10 \%$. The pressure is fixed at $0.4 \mathrm{~Pa}$ and the magnetron power at $100 \mathrm{~W}$ for all the results presented in this paper.

\subsection{TD-LIF, TD-LAS and deposition arrangements}

The laser source is a tuneable diode blue-laser system, Toptica Phototonics DL $100(15 \mathrm{~mW})$, single mode operated with 


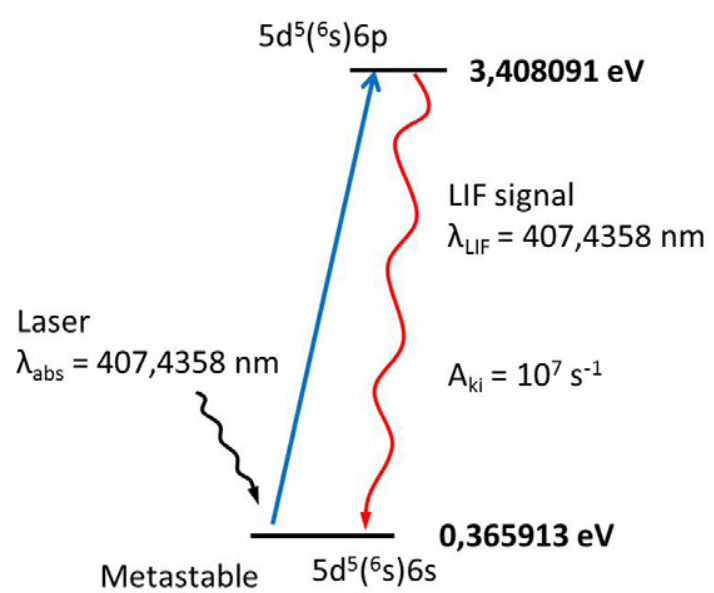

Figure 2. Grotrian diagram.

resonance transition centred at a $\lambda_{0}(\mathrm{~W})=407.4358 \mathrm{~nm}$ wavelength, which corresponds to the neutral $\mathrm{W}$ transition from the low energy $(0.37 \mathrm{eV})$ metastable level $5 \mathrm{~d}^{5}\left({ }^{6} \mathrm{~S}\right) 6 \mathrm{~s}$ to radiative excited level $5 d^{5}\left({ }^{6} \mathrm{~S}\right) 6 \mathrm{p}$ (figure 2). In this study, as shown in section 3.2, the TD-LAS, TD-LIF and deposition rate measurements suggest a low sensitivity to the electron density $\left(n_{\mathrm{e}}\right)$ variations of the metastable level $5 \mathrm{~d}^{5}\left({ }^{6} \mathrm{~S}\right) 6 \mathrm{~s}$. Consequently, this may be considered as being representative of the $\mathrm{W}$ neutral ground state.

The diode laser spectral resolution is $0.005 \mathrm{pm}$ which is much narrower than that of an OPO laser $(\sim 2 \mathrm{pm})$ or a dye $\mathrm{Nd}$ :YAG laser $(\sim 0.5 \mathrm{pm})$. The typical scanning frequency is $60 \mathrm{~Hz}$. Keeping the diode temperature constant and systematically controlling the current, the scanning range available, without cavity mode jump, is about $8 \mathrm{pm}$. The laser beam is separated via a beam splitter into two beams. One probes the plasma volume while the other one passes through a Fabry-Pèrot interferometer to calibrate the wavelength $(\Delta \lambda=$ $\left.\lambda_{\text {laser }}-\lambda_{0}\right)$ [12].

Figure 3 presents a schematic view of the optical arrangements used for TD-LAS (figure 3(a)) and TD-LIF (figure 3(b)) measurements. The absorption and fluorescence wavelengths are the same around $\lambda_{0}$ (a two energy level system, figure 2). To perform TD-LAS measurements, the laser beam is positioned in the direction parallel to the target at $z=9 \mathrm{~cm}$ (the distance required for calibration, see section 3.2) corresponding to position (1) of the magnetron (figure 1). The light passing through the quartz windows mounted on long pipes is collected by a photodiode. The characteristic absorption curve is determined by measuring the intensity $I_{0}$ emitted by the laser diode and the light beam intensity $I_{\mathrm{t}}$ transmitted after crossing the plasma, and calculating the absorption profile resulting from the Beer-Lambert law (1), where $L$ is the absorption length and $k(\lambda, n)$ (a product of the attenuation cross section $\sigma(\lambda)$ and the atoms' density $n$ ) is the attenuation coefficient at the wavelength $\lambda$.

$$
k(\lambda, n) \cdot L=\sigma(\lambda) \cdot n \cdot L=-\ln \left(\frac{I_{\mathrm{t}}}{I_{0}}\right) .
$$

To perform the TD-LIF measurements, the position of the magnetron is switched from position (1) to position (2) to avoid changing the position of the laser diode. In this setup, the target is placed in front of the laser beam. The latter is positioned in the direction perpendicular to the target surface and placed in the centre of the racetrack where $\mathrm{W}$ atoms are sputtered. The fluorescence emitted from the probed volume $\left(1 \times 1 \times 3 \mathrm{~mm}^{3}\right)$ for several distances $z$ from the target is focused by a lens (focal length of $30 \mathrm{~cm}$ ) into an optical fibre. The TD-LIF signal is carried into a monochromator (Chromex 500 IS/IM) which is set to $\lambda_{0}$ and converted into an electrical signal using a photomultiplier tube (Hamamatsu R928). The tube output is connected to a current amplifier (SRS 570) and recorded with a digital oscilloscope (Lecroy Wavesurfer no 104Xi).

Deposition on silicon substrates (with preliminary cleaning in acetone and a methanol ultrasound bath) is performed making use of a substrate holder positioned in front of the magnetron cathode (figure 1, position (1)). The thickness of the deposition profile was measured using scanning electron microscopy.

\section{Results and discussion}

\subsection{TD-LIF experimental and data analysis procedures}

In this study, the particularities of $\mathrm{W}$ such as isotopes with their respective resonance wavelength shifts have to be taken into account. In the available scanning range, the high spectral resolution of the laser diode $\left(5 \times 10^{-3} \mathrm{pm}\right)$ allows one to clearly distinguish two well-defined populations of $\mathrm{W}$ corresponding to thermalized and energetic sputtered atoms and leading to the study of the general behaviour of heavy sputtered species transport. In this section the method used for the analysis of the TD-LIF signal is presented.

At low pressure, i.e. with limited quenching processes, and with conditions for which we checked that the absorption saturation does not occur, the LIF signal intensity can be considered to be directly proportional to the probed particles' density. The wavelength scale of the laser diode scanning range is converted into velocity scale using $v=c \cdot \Delta \lambda / \lambda$. The TD-LIF signal then represents the AVDF of the W sputtered atoms. Figure 4 shows a typical shape of the TD-LIF signal recorded at $z=0.8 \mathrm{~cm}$ in the axial direction in front of the target racetrack.

The isotope shifted resonance wavelengths and the hyperfine structures of the transitions at 384.8620, 400.8750 and $407.4358 \mathrm{~nm}$ were measured in [18]. W has five isotopes whose natural abundances and shifts are given in table 1 . The isotopes ${ }^{180} \mathrm{~W},{ }^{182} \mathrm{~W},{ }^{184} \mathrm{~W}$ and ${ }^{186} \mathrm{~W}$ have a nuclear spin of 0 while ${ }^{183} \mathrm{~W}$ has a nuclear spin of $1 / 2$ giving rise to hyperfine structure. For the considered transition at $\lambda_{0}=407.4358 \mathrm{~nm}$, the contributions of ${ }^{180} \mathrm{~W}$ (with $0.12 \%$ natural abundance) and the hyperfine state of ${ }^{183} \mathrm{~W}$ are negligible. Another transition such the one at $400.8750 \mathrm{~nm}$ would make the data analysis more challenging because of line blending issues (singly ionized tungsten lines being coincidentally at nearly the same wavelength as the neutral lines). Also, the transition at $384.8620 \mathrm{~nm}$ shows a significant contribution of the hyperfine state of ${ }^{183} \mathrm{~W}$ masking the ${ }^{180} \mathrm{~W}$ peaks. That is why we chose the transition at $\lambda_{0}=407.4358 \mathrm{~nm}$. 

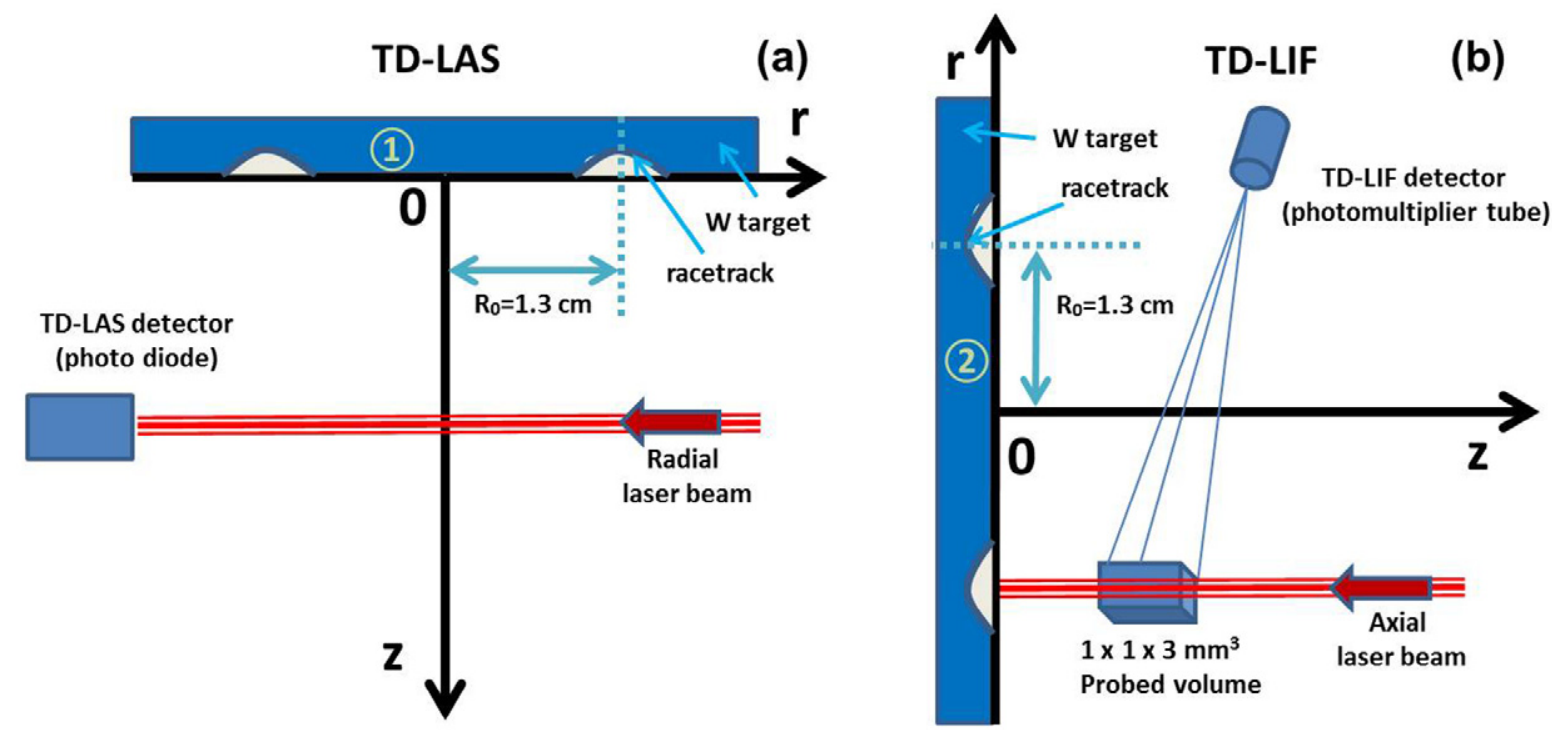

Figure 3. (a) Experimental set-up for TD-LAS measurements of sputtered $\mathrm{W}$ atoms in the parallel direction $(r$-axis) to the target surface. (b) Experimental set-up for TD-LIF measurements of sputtered W atoms along the magnetron cathode axis $z$.

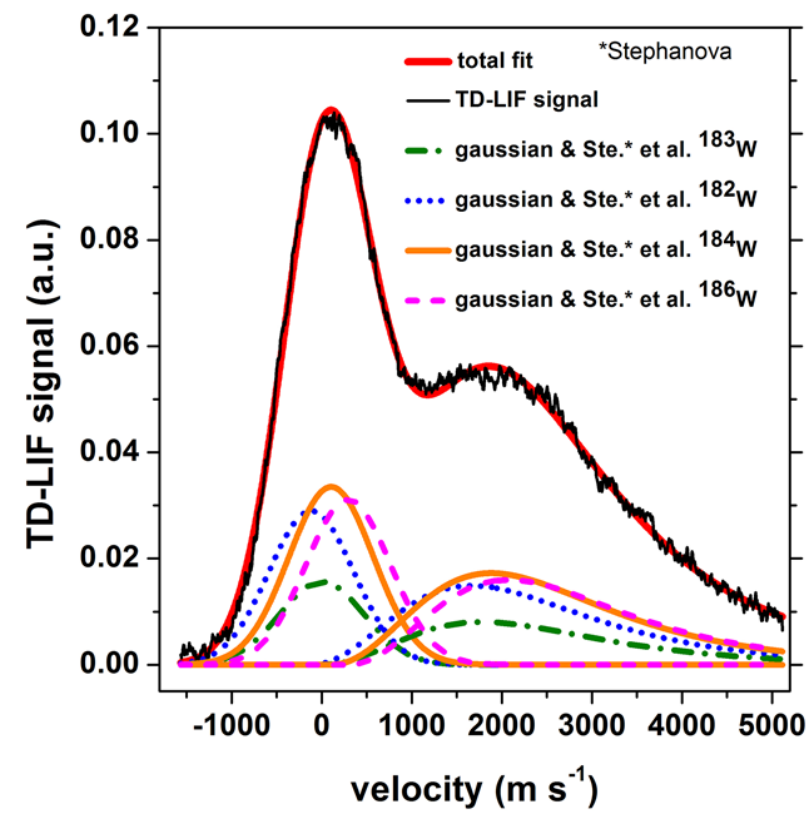

Figure 4. Typical TD-LIF signal recorded at $z=0.8 \mathrm{~cm}$ and $R_{0}=1.3 \mathrm{~cm}$ fitted with four Gaussians (thermalized atoms) and four functions (energetic atoms) of Stephanova et al [20]. The velocity scale is arbitrarily centred on the maximum of the thermalized population of ${ }^{183} \mathrm{~W}$.

Then, the symmetrical part of the signal corresponding to thermalized $\mathrm{W}$ atoms is fitted with a Gaussian distribution function for each isotope with its corresponding shift and natural abundance but the same full width at half maximum (FWHM) as they have the same temperature. The latter was assumed considering the slight difference of mass between $\mathrm{W}$ isotopes $(\sim 2 \%)$. In the fitting procedure the isotope shifts and the height ratios (accounting for isotope natural abundance) are fixed.

Note that in our conditions, Doppler broadening is typically of $1.5 \mathrm{pm}$ which is much higher than the laser spectral
Table 1. Tungsten isotopes with natural abundance and resonance shift.

\begin{tabular}{llcll}
\hline $\begin{array}{l}\text { Index } \\
i\end{array}$ & Isotopes & $\begin{array}{l}\text { Natural } \\
\text { abundance }(\%)\end{array}$ & $\begin{array}{l}\text { Resonance } \\
\text { shift (pm) }\end{array}$ & $\begin{array}{l}\lambda_{i} \\
(\mathrm{~nm})\end{array}$ \\
\hline 0 & ${ }^{180} \mathrm{~W}$ & 0.12 & -0.36 & 407.4314 \\
1 & ${ }^{182} \mathrm{~W}$ & 26.50 & -0.16 & 407.4334 \\
2 & ${ }^{183} \mathrm{~W}$ & 14.31 & 0 & 407.4350 \\
3 & ${ }^{184} \mathrm{~W}$ & 30.64 & 0.14 & 407.4364 \\
4 & ${ }^{186} \mathrm{~W}$ & 28.43 & 0.40 & 407.4390 \\
\hline
\end{tabular}

resolution of $5 \times 10^{-3} \mathrm{pm}$. In figure 4 the origin of the velocity scale is arbitrary fixed with the maximum of the thermalized population of the ${ }^{183} \mathrm{~W}$ isotope with the corresponding isotropic Doppler profile in the laser beam direction. The ${ }^{183} \mathrm{~W}$ atoms with negative velocities mean that they travel in the laser beam direction (towards the target) and the opposite (towards the substrate) for positive values. The asymmetrical part of the signal with positive velocities corresponds to energetic W sputtered atoms (anisotropic distribution function). Considering the physics of sputtering, the energetic distribution can be fitted by a Thompson's distribution function. The initial energy of the sputtered atoms immediately leaving the target surface obeys Thompson's formula (equation (2) [19]).

$$
J_{\mathrm{T}}(v) \propto \frac{1}{2} M v^{2}\left(\frac{1}{2} M v^{2}+U\right)^{-3+2 m}
$$

where $m$ is the binary interaction parameter, $M$ the mass of the sputtered atoms, $v$ the velocity of the sputtered atoms and $U$ is the value of the surface energy barrier. To improve the sputtered atoms' fitting, the following empirical modification of a previous distribution function proposed by Stephanova et al [20] is required:

$$
J_{\mathrm{T} M}(v)=J_{\mathrm{T}}(v)\left[1-\left(\frac{\frac{1}{2} M v^{2}+U}{\frac{1}{2} M v_{\max }^{2}+U}\right)\right] .
$$



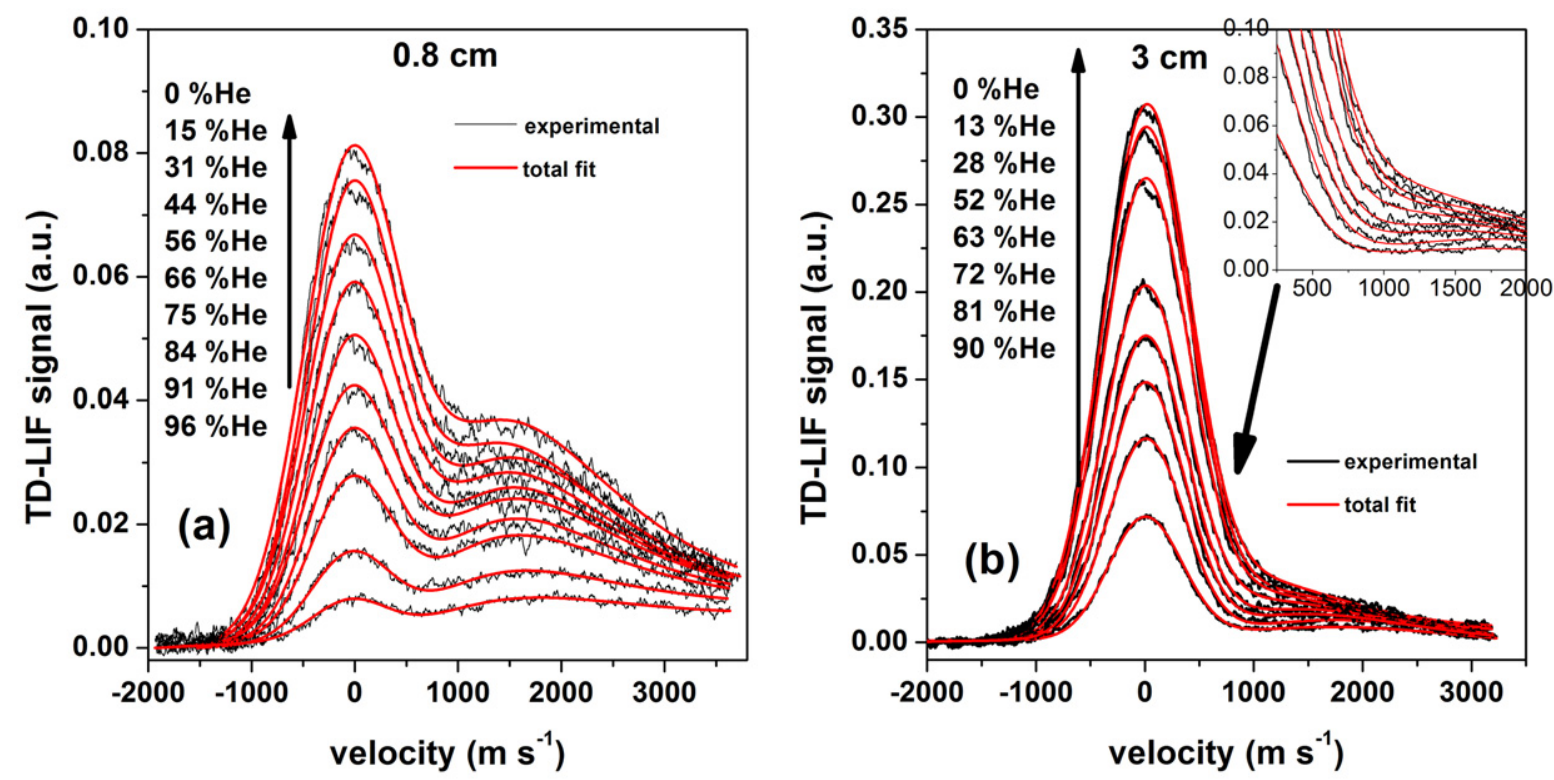

Figure 5. TD-LIF signals with total fits at $z=0.8 \mathrm{~cm}(a)$ and $z=3 \mathrm{~cm}(b)$ (four Gaussians + four Stephanova et al functions) for several Ar-He mixtures. The velocity scale is arbitrarily centred on the maximum of thermalized population of ${ }^{183} \mathrm{~W}$. The measurements were performed at $R_{0}=1.3 \mathrm{~cm}$; pressure $=0.4 \mathrm{~Pa}$; magnetron power $=100 \mathrm{~W}$.
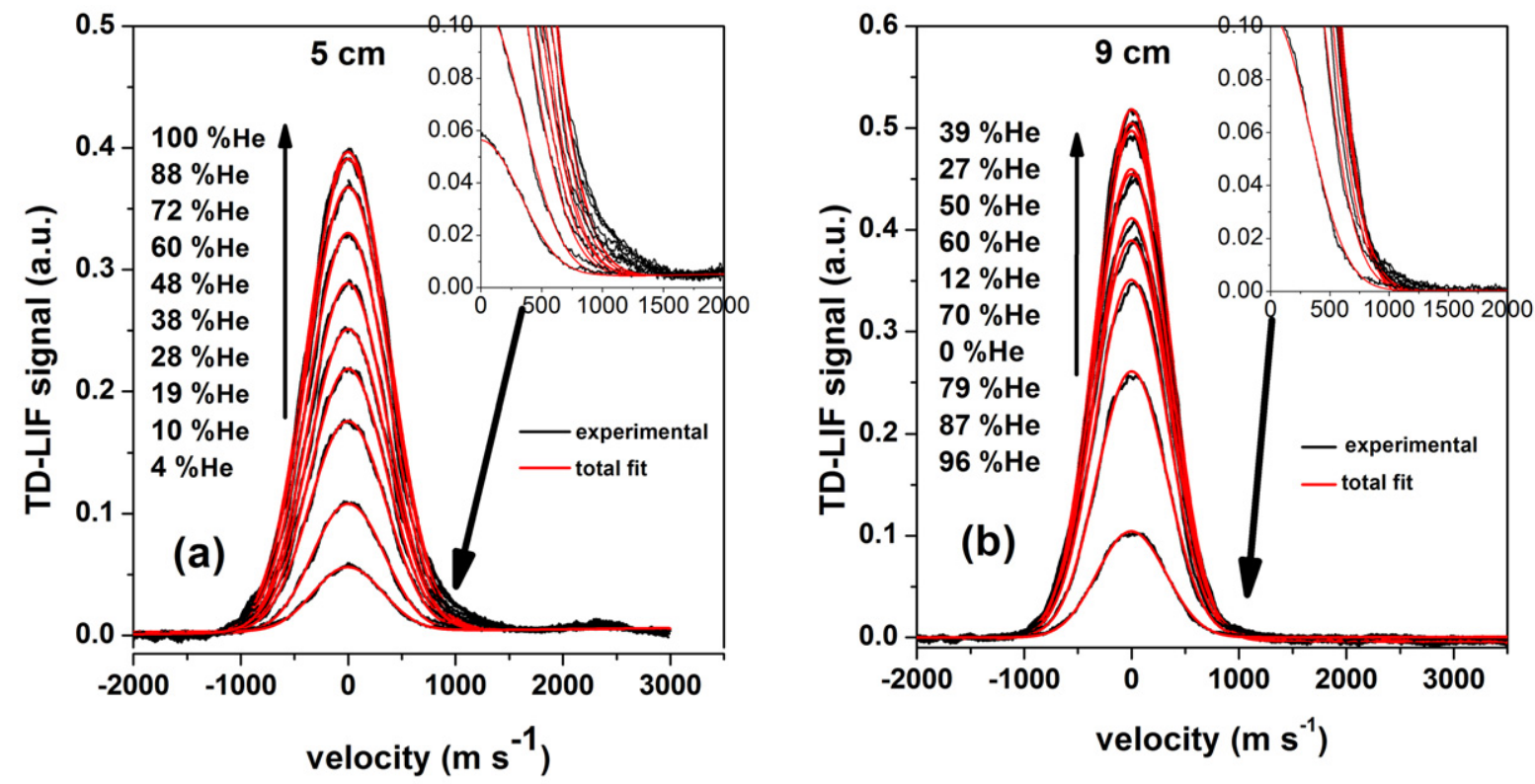

Figure 6. TD-LIF signals with total fits at $z=5 \mathrm{~cm}(a)$ and $z=9 \mathrm{~cm}(b)$ (only four Gaussians) for several Ar-He mixtures. The velocity scale is arbitrarily centred on the maximum of the thermalized population of ${ }^{183} \mathrm{~W}$. The measurements were performed at $R_{0}=1.3 \mathrm{~cm}$; pressure $=0.4 \mathrm{~Pa}$; magnetron power $=100 \mathrm{~W}$.

This provides a cut off velocity $v_{\max }$ which represents the limit of the velocity distribution function. In our data analysis, $v_{\max }$ is fixed at $1 \times 10^{4} \mathrm{~m} \mathrm{~s}^{-1}$ to take into account the whole energetic tails, $U=1.4 \times 10^{-18} \mathrm{~J}(8.8 \mathrm{eV})[21], m=0.2$ [20]. The AVDF is then fitted with a group of four Gaussians and a group of four Stephanova et al [20] distribution functions. An additional constraint is that, for each isotope, the maximum of the Gaussian distribution function $(v=0)$ corresponds to the starting point of the Stephanova et al one since energetic particles only have positive velocities (towards the substrate). Figures 5 and 6 show the raw signals (black lines) with their corresponding total fits (red lines) for several Ar-He mixtures at $z=0.8 \mathrm{~cm}$ (figure $5(a)$ ), $z=3 \mathrm{~cm}$ (figure $5(b)), z=5 \mathrm{~cm}$ (figure 6(a)) and $z=9 \mathrm{~cm}$ (figure $6(b)$ ).

As expected, the intensity of the TD-LIF signal drastically decreases with the increase of $\% \mathrm{He}$ due to a lower sputtering as $M_{\mathrm{He}} \ll M_{\mathrm{Ar}}$. At $z=0.8$ and $3 \mathrm{~cm}$, the two populations can be clearly distinguished from $z=5 \mathrm{~cm}$ where only a small fraction of energetic sputtered atoms remains (the discrepancy between the black and red lines in the inset). Nevertheless at this distance, the information about energetic atoms cannot be extracted because their density is too low to be fitted with the 

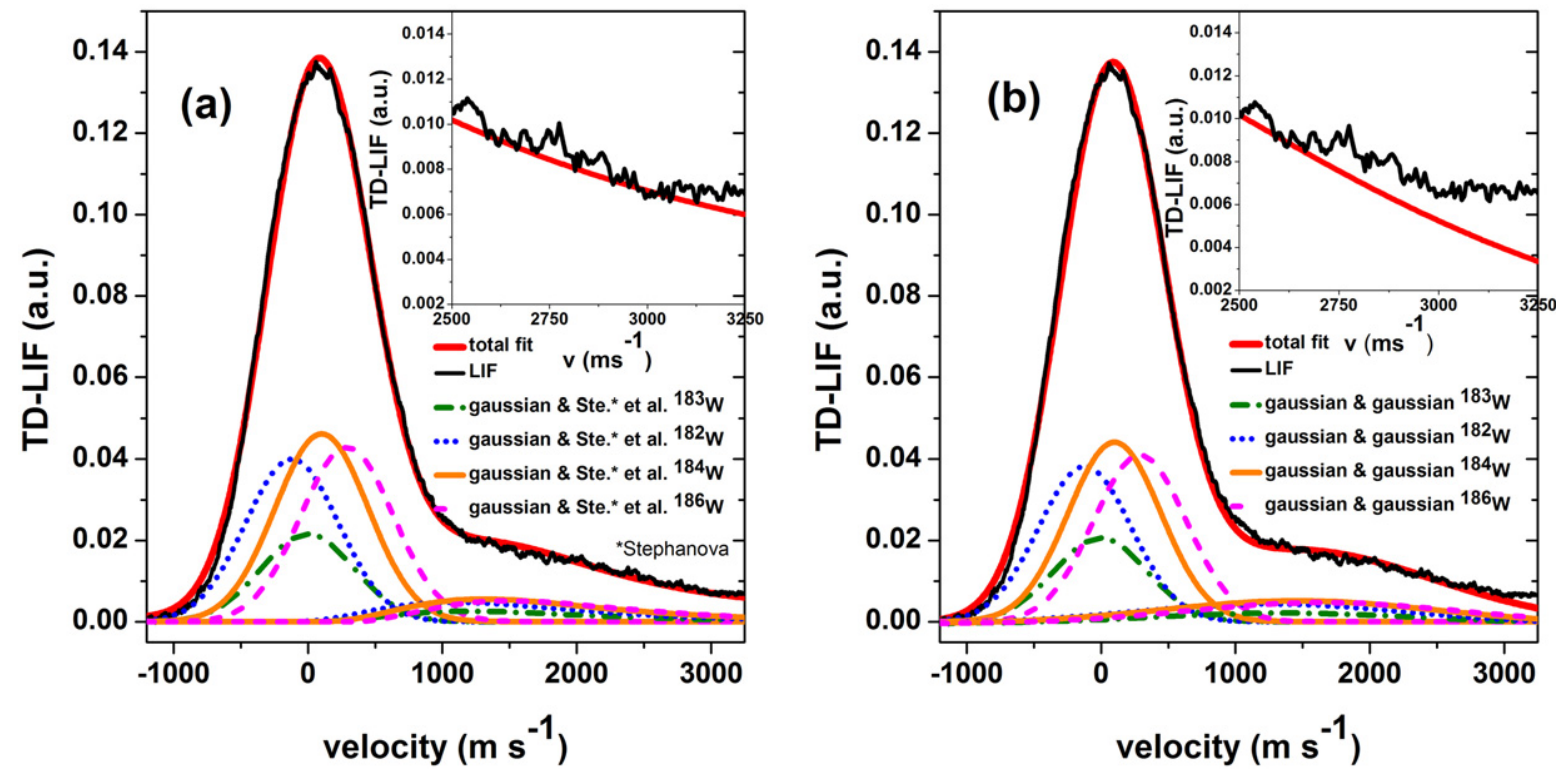

Figure 7. (a) A TD-LIF signal recorded at $z=3 \mathrm{~cm}$ and $R_{0}=1.3 \mathrm{~cm}$ fitted with four Gaussians (thermalized atoms) and four Stephanova et al [20] functions (energetic atoms). (b) The same TD-LIF signal fitted with eight Gaussians (four for thermalized and four for energetic atoms). The velocity scale is arbitrarily centred on the maximum of the thermalized population of ${ }^{183} \mathrm{~W}$. Pressure $=0.4 \mathrm{~Pa}$; magnetron power $=100 \mathrm{~W}$; pure Ar.

four Stephanova et al distribution functions. At $z=9 \mathrm{~cm}$, no more energetic atoms can be detected (no discrepancy between the black and red lines in the inset). Interestingly, at $3 \mathrm{~cm}$ it is still suitable to fit the energetic part of the TD-LIF signal with Stephanova et al distribution functions (figure $7(a)$ ) as the use of Gaussian functions leads to discrepancies in the tail of the energetic distribution (figure 7(b)). Even if W sputtered atoms undergo a few collisions, the deviation is not significant due to the great difference in mass between $\mathrm{W}$ and the buffer gas atoms $\mathrm{Ar}$ (and even more with $\mathrm{He}$ ). Consequently, after a few collisions, the energetic $\mathrm{W}$ atoms keep their original velocity anisotropy pointed towards the substrate. For such heavy sputtered atoms, the velocity direction seems to be confined in the initial emission cone [22] and thus the atoms crossing the probed volume keep the local information of the sputtering, i.e. the ejection angles and velocities distribution at the target surface $z=0$, even at $z=3 \mathrm{~cm}$. Considering an Ar or He background gas at a pressure of $0.4 \mathrm{~Pa}$ and a gas temperature of $500 \mathrm{~K}$, the mean free path of $\mathrm{W}$ atoms is of the order of few centimetres. Note that, in the case of numerous collisions which are efficient in terms of energy transfer and deviation, Stephanova et al's distribution function would no longer be suitable to fit the energetic W atoms' TD-LIF signals obtained far from the target. This might be the case for $\mathrm{Ti}$ or $\mathrm{Al}$ atoms where one would use Gaussian distribution functions.

\subsection{Calibration of TD-LIF using TD-LAS}

The main advantage of TD-LIF calibrated with TD-LAS is to obtain local quantitative measurements on both energetic and thermalized $\mathrm{W}$ sputtered atoms. The use of TD-LAS is, however, restricted to conditions for which the absorption can be assumed to be homogeneous along the laser beam pathway; therefore in the volume where the absorbing particles

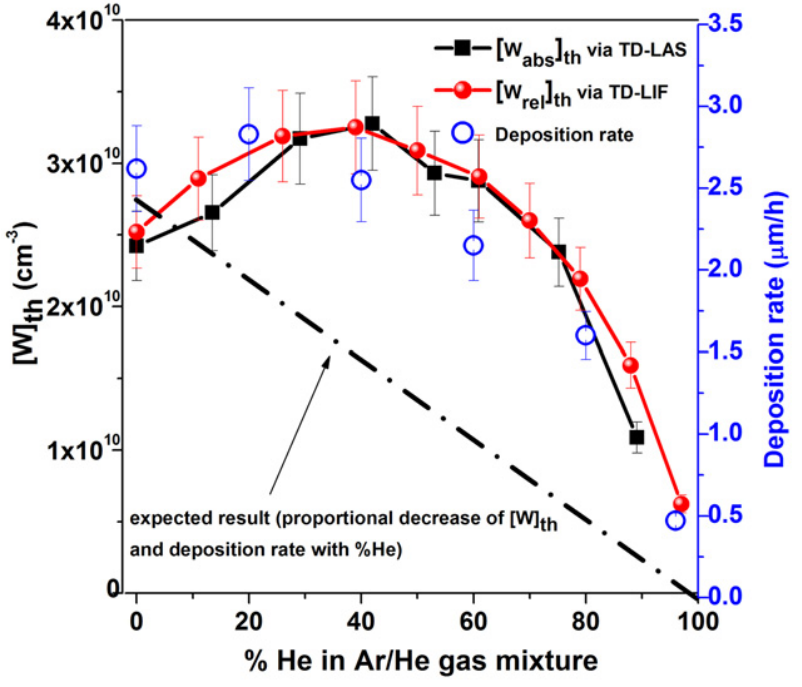

Figure 8. $[\mathrm{W}]_{\text {th }}$ measured by means of TD-LIF (relative values) and TD-LAS (absolute values) in addition to the deposition rate as a function of $\% \mathrm{He}$. The measurements were performed at $z=9 \mathrm{~cm}$ and $R_{0}=1.3 \mathrm{~cm}$; pressure $=0.4 \mathrm{~Pa}$; magnetronpower $=100 \mathrm{~W}$.

are thermalized, i.e. far from the target or at high pressure. Since the TD-LAS method integrates the local information along the laser beam pathway, the laser beam is positioned in the direction parallel to the target at $z=9 \mathrm{~cm}$, where only thermalized $\mathrm{W}$ atoms are measured (as shown in the previous sub-section, figure 6). Figure 8 represents the density of $\mathrm{W}$ thermalized atoms $\left([\mathrm{W}]_{\mathrm{th}}\right)$ measured above the centre of the racetrack (at $R_{0}=1.3 \mathrm{~cm}$ ) by means of TD-LIF (relative density without calibration) and TD-LAS as well as the deposition rate as a function of $\% \mathrm{He}$.

The total TD-LAS signal is fitted with four Gaussians. The experimental maxima of the four absorbance profiles 
(equation (1), $k_{\exp }\left(\lambda=\lambda_{\mathrm{i}}\right)$ ) and the $\lambda_{\mathrm{FWHM}}$ are determined to calculate the total absolute value of $\left[\mathrm{W}_{\mathrm{abs}}\right]_{\mathrm{th}}\left(\mathrm{cm}^{-3}\right)(4)$. The corresponding calculated temperature (5) is in the range of $400-500 \mathrm{~K}$ (respectively $230-260 \mathrm{~m} \mathrm{~s}^{-1}$ ). Thus, at such a long distance, the variation of the atoms' velocity is not significant.

$$
\begin{gathered}
{\left[\mathrm{W}_{\mathrm{abs}}\right]_{\mathrm{th}}=\sum_{i=1}^{4} \frac{k_{\mathrm{exp}}\left(\lambda_{i}\right) \cdot \Delta \lambda_{\mathrm{FWHM}}}{8.25 \times 10^{-13} \cdot f \cdot \lambda_{i}^{2}}} \\
T_{\mathrm{W}}=\left(\frac{\Delta \lambda_{\mathrm{FWHM}}}{\lambda_{i}} \cdot \frac{1}{7.16 \times 10^{-7}}\right)^{2} \cdot M_{\mathrm{W}},
\end{gathered}
$$

where $\Delta \lambda_{\text {FWHM }}\left(\mathrm{cm}^{-1}\right)$ is the FWHM of each Gaussian distribution fitting the absorbing profile, $k_{\exp }\left(\mathrm{cm}^{-1}\right)$ is the attenuation coefficient given by the Lambert-Beer law, $f$ is the oscillator strength of the transition $\left(f=2.5 \times 10^{-2}\right)$, $\lambda_{i}\left(\mathrm{~cm}^{-1}\right)$ is the resonance wavelength with $i$ the index of the corresponding isotope (see table 1 ), and $M_{\mathrm{W}}$ (uma) and $T_{\mathrm{W}}(\mathrm{K})$ are the mass and the temperature of $\mathrm{W}$, respectively. From the TD-LIF signal the relative $\left[\mathrm{W}_{\text {rel }}\right]$ is calculated by determining the area of the AVDF

$$
\left[\mathrm{W}_{\mathrm{rel}}\right]=\int_{-\infty}^{+\infty} \operatorname{AVDF} \mathrm{d} v
$$

Measurements by TD-LIF and TD-LAS are in very good agreement $\left(\left[\mathrm{W}_{\text {rel }}\right]_{\mathrm{th}}=\left[\mathrm{W}_{\mathrm{abs}}\right]_{\mathrm{th}}=[\mathrm{W}]_{\mathrm{th}}\right)$ and are supported by the deposition rate on silicon substrates making the calibration possible. Additional measurements on $n_{e}$ (not shown here) indicate an increase at $z=9 \mathrm{~cm}$ by a factor of 3 between $\% \mathrm{He}=0$ and 80 while the metastable level measurements are in good agreement with deposition rate. In fact, $n_{\mathrm{e}}$ seems to not impact the measured metastable densities. This suggests a low sensitivity to $n_{\mathrm{e}}$ of the metastable level $5 \mathrm{~d}^{5}\left({ }^{6} \mathrm{~S}\right) 6 \mathrm{~s}$. Thus, the latter may be produced close to the target (where the electron density is high) and then diffuses up to the measurement location. Consequently, measurements are considered as being representative of the $\mathrm{W}$ neutral ground state. The TD-LIF relative measurements $\left(\left[\mathrm{W}_{\text {rel }}\right]_{\text {th }}\right.$ and $\left.\left[\mathrm{W}_{\text {rel }}\right]_{\mathrm{en}}\right)$ are then rescaled for each condition using the consistency at $z=9 \mathrm{~cm}$ between the TD-LIF signal and $\left[\mathrm{W}_{\mathrm{abs}}\right]_{\mathrm{th}}$. Thus it becomes possible to obtain a local quantitative estimate of the AVDF and the density of both energetic and thermalized $\mathrm{W}$ atoms along the magnetron cathode axis.

The observed maximum of $[\mathrm{W}]_{\mathrm{th}}$ and the deposition rate at $20-40 \% \mathrm{He}$ is not a consequence of the variation of the current and the voltage with $\% \mathrm{He}$. Indeed, as shown in figure 9 , the voltage decreases and the current increases only by $10 \%$ from 0 to $90 \% \mathrm{He}$ and both are quasi-constant up to $40-50 \%$. As detailed in the following sub-section, this behaviour could be the consequence of an improved transport and an increase of the ratio of argon ions to argon neutrals $\left(\mathrm{Ar}^{+} / \mathrm{Ar}\right)$ with the increase of $\% \mathrm{He}$. This effect would overcome the lower sputtering of $\mathrm{W}$ with higher He content.

\subsection{Velocities and fluxes of thermalized and energetic $W$ sputtered atoms}

In this section we report absolute measurements along the axial magnetron cathode axis of AVDF, FVDF, density ([W]),

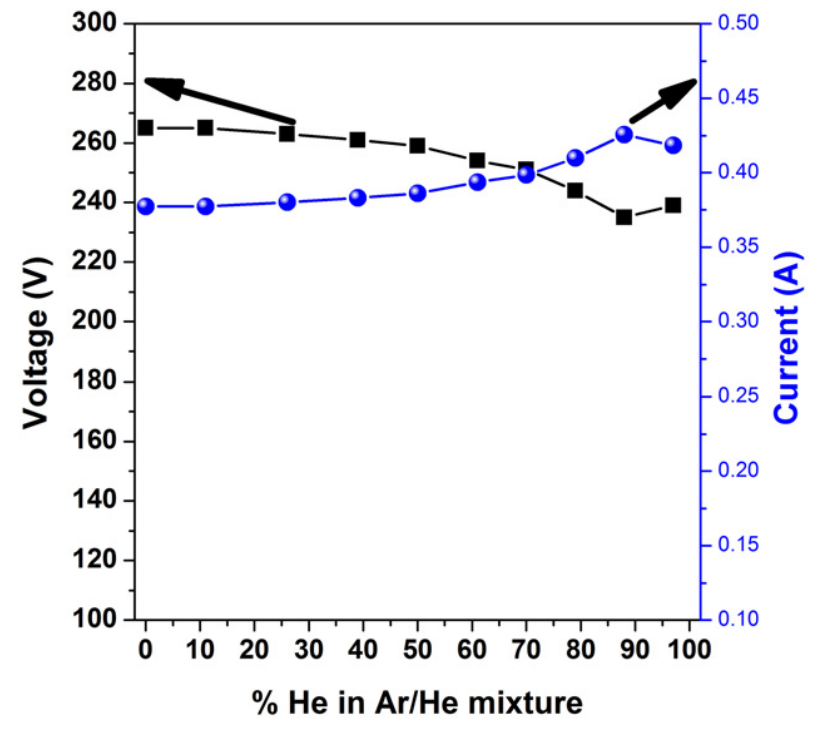

Figure 9. Cathode voltage and current as a function of $\% \mathrm{He}$ in $\mathrm{Ar}-\mathrm{He}$ mixture. Pressure $=0.4 \mathrm{~Pa}$; magnetron power $=100 \mathrm{~W}$.

flux $(\Phi)$ as well as the mean velocity $\left\langle v_{z}\right\rangle$ of energetic atoms. The absolute FVDF was obtained by multiplying the absolute AVDF with the corresponding velocity $(\operatorname{FVDF}(v)=v$. $\operatorname{AVDF}(v))$. Then, the fluxes of thermalized $\left(\Phi_{\mathrm{th}}\right.$, directed towards the substrate) and energetic $\left(\Phi_{\text {en }}\right)$ W atoms were calculated by determining the area of the absolute FVDF for each population (7). The mean velocity $\left\langle v_{z}\right\rangle$ of energetic atoms was deduced using (8).

$$
\begin{gathered}
\Phi=\int_{0}^{+\infty} \text { FVDF } \mathrm{d} v \\
\left\langle v_{z}\right\rangle=\frac{\int_{0}^{+\infty} \text { FVDF } \mathrm{d} v}{\int_{0}^{+\infty} \operatorname{AVDF} \mathrm{d} v} .
\end{gathered}
$$

The purpose is the characterization of the gas mixture effect on the transport of thermalized and energetic W atoms. Figure 10 shows the absolute $\operatorname{AVDF}(a)$ and $\operatorname{FVDF}(b)$ obtained by TD-LIF at $z=0.8 \mathrm{~cm}\left(R_{0}=1.3 \mathrm{~cm}\right)$ as a function of $\mathrm{Ar}-\mathrm{He}$ gas mixtures ranging from 0 to $96 \% \mathrm{He}$, by fitting the raw signals of figure $5(a)$.

In this range of $\mathrm{He}$ content, population densities are $4 \times 10^{8} \leqslant[\mathrm{~W}]_{\mathrm{th}} \leqslant 7 \times 10^{9} \mathrm{~cm}^{-3}$ and $2 \times$ $10^{9} \leqslant[\mathrm{~W}]_{\mathrm{en}} \leqslant 1 \times 10^{10} \mathrm{~cm}^{-3}$ with corresponding fluxes $\Phi_{\text {th }}$ and $\Phi_{\text {en }}$ of $1 \times 10^{13}-3 \times 10^{14}$ atoms $\mathrm{cm}^{-2} \mathrm{~s}^{-1}$ and $4 \times 10^{14}-3 \times 10^{15}$ atoms cm $\mathrm{cm}^{-2} \mathrm{~s}^{-1}$, respectively. The densities of thermalized and energetic atoms are in the same order of magnitude while their fluxes are about ten times higher for $\Phi_{\mathrm{en}}$. Indeed, close to the target and for all mixtures, $\Phi_{\text {en }}$ prevails compared to $\Phi_{\text {th }}$ due to the higher velocity of energetic $\mathrm{W}$ atoms. Far away from the target where sputtered atoms have the same energy (only a thermalized population with slow variation of temperature), the behaviour of the density is comparable to the flux one. Thus, it justifies the comparison between the densities and the deposition rate in figure 8 . However, close to the target, where thermalized 

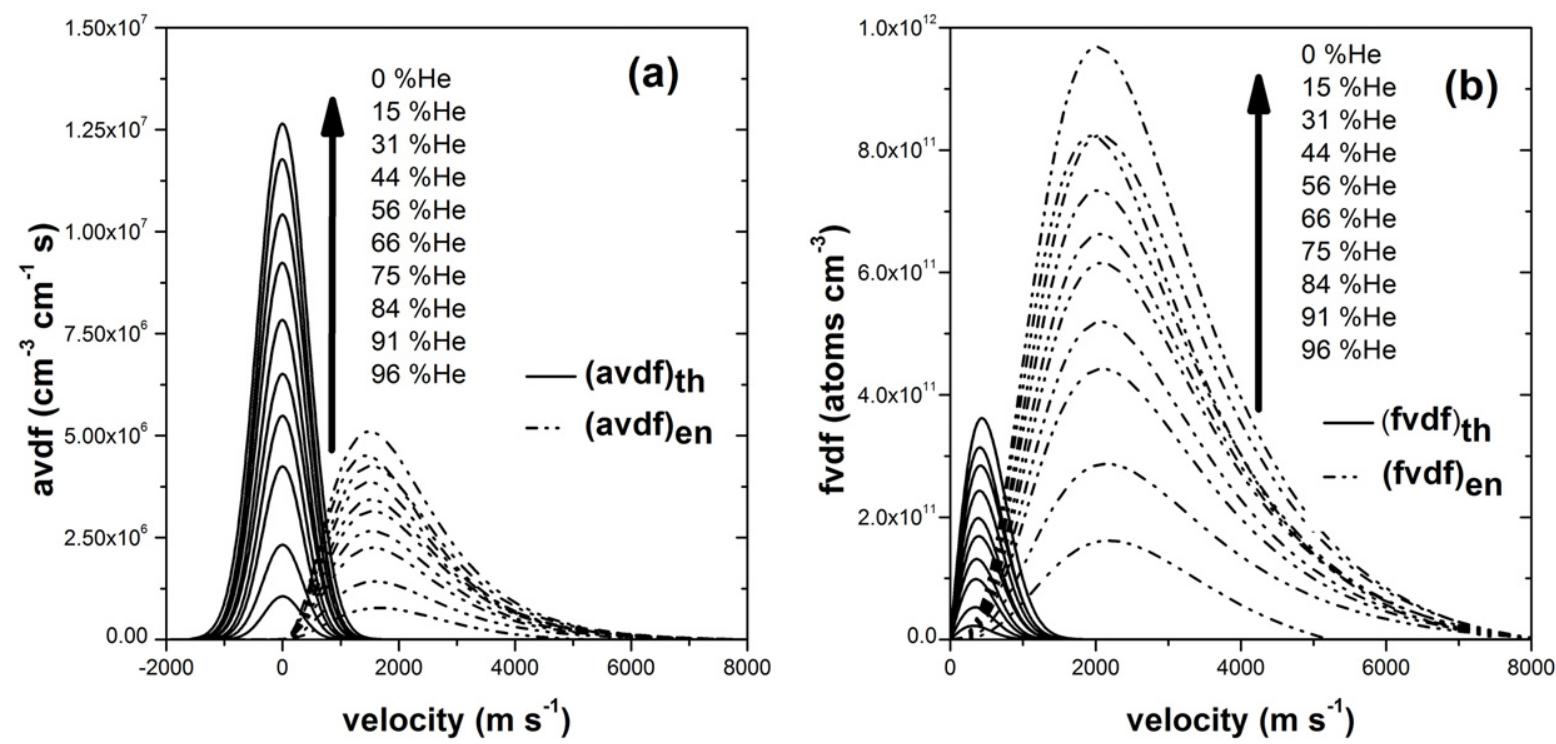

Figure 10. $(a)$ Absolute AVDF of thermalized $\left(\mathrm{AVDF}_{\mathrm{th}}\right)$ and energetic $\left(\mathrm{AVDF}_{\mathrm{en}}\right)$ populations. $(b)$ Corresponding absolute FVDF of thermalized $\left(\mathrm{FVDF}_{\mathrm{th}}\right)$ and energetic $\left(\mathrm{FVDF}_{\mathrm{en}}\right)$ populations. The measurements were performed at $z=0.8 \mathrm{~cm}$ and $R_{0}=1.3 \mathrm{~cm}$; pressure $=0.4 \mathrm{~Pa}$; magnetron power $=100 \mathrm{~W}$.

and energetic atoms have very different transport properties or behaviour in terms of velocities and directions (anisotropic and isotropic), the important parameter to consider is the flux (and not only the particle density). The flux governs the transport, in which the thermalization process takes part as well as the deposition properties. Also, the flux of energetic atoms $\Phi_{\text {en }}$ at the vicinity of the target where the collisional process is limited (here at $0.8 \mathrm{~cm}$ which is the closest distance accessible because of the magnetron top protection) leads to the proportion of W sputtering with respect to the gas mixture. Figure 11 presents $\Phi_{\mathrm{en}}$ at $z=0.8 \mathrm{~cm}\left(R_{0}=1.3 \mathrm{~cm}\right)$ as a function of the $\% \mathrm{He}$.

One can observe the non-linear decrease of $\Phi_{\text {en }}$ which is lower than the expected behaviour (dashed line). Considering the mass of $\mathrm{He}$ to be extremely low and so likewise the sputtering yield $(Y)$ of $\mathrm{W}$ by $\mathrm{He}$, the ions participating in the sputtering are mainly Arions since $Y_{\mathrm{Ar}} / Y_{\mathrm{He}} \approx 300$ (incident ions' energy $\approx 250 \mathrm{eV}$ (figure 9), $Y_{\mathrm{He}}=3 \times 10^{-3}$ atoms/ion, $Y_{\mathrm{Ar}}=9 \times 10^{-1}$ atoms/ion [23]). Consequently, the decrease of $\Phi_{\text {en }}$ should follow the decrease of $\%$ Ar. In our plasma conditions, it is clear that the populations of ions $\left(\mathrm{He}^{+}, \mathrm{Ar}^{+}\right)$ do not reflect the Ar-He gas mixture variations. Moreover, $\Phi_{\text {en }}$ remains significant and so the sputtering of $\mathrm{W}$, even at $80 \% \mathrm{He}$ $\left(\Phi_{\mathrm{en}}=1.3 \times 10^{14}\right.$ atoms cm $\left.\mathrm{cm}^{-2} \mathrm{~s}^{-1}\right)$. This could be explained by a more important $\mathrm{Ar}^{+} / \mathrm{Ar}$ ratio in the sputtering plasma than expected. In fact, it is well known that the He excitation and ionization energies are higher than the Ar ones (see table 2).

Additionally, the $\mathrm{He}$ ionization cross section $\left(\sigma_{\mathrm{He}^{+}}\right)$is about six times lower than the Ar one $\left(\sigma_{\mathrm{Ar}^{+}}\right)$in our experiment's secondary electron energy range (secondary electron energy = $250 \mathrm{eV}, \sigma_{\mathrm{Ar}^{+}}=2 \times 10^{-20} \mathrm{~m}^{2}, \sigma_{\mathrm{He}^{+}}=0.3 \times 10^{-20} \mathrm{~m}^{2}$ [24]). Also, the secondary emission $\gamma_{\mathrm{se}}$ of $\mathrm{W}$ by $\mathrm{He}$ is two and a half times more important than by Ar (incident ions' energy $\approx 250 \mathrm{eV}, \gamma_{\mathrm{se}-\mathrm{He}}=0.25$ electrons/ion and $\gamma_{\mathrm{se}-\mathrm{Ar}}=0.10$ electrons/ion [25]). Thus, as seen in figure 11 in the change of curvature around $80 \% \mathrm{He}$, it seems that

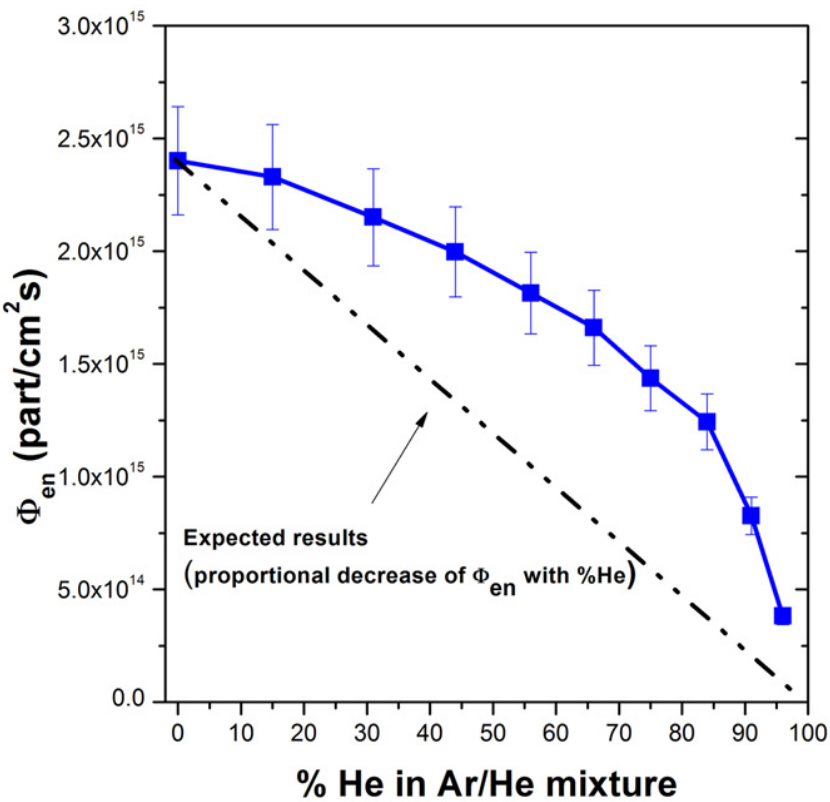

Figure 11. $\Phi_{\mathrm{en}}$ as function of the $\% \mathrm{He}$ in an $\mathrm{Ar}-\mathrm{He}$ gas mixture. The measurements were performed at $z=0.8 \mathrm{~cm}$ and $R_{0}=1.3 \mathrm{~cm}$; pressure $=0.4 \mathrm{~Pa}$; magnetron power $=100 \mathrm{~W}$.

there is a change in the $\mathrm{Ar}^{+} / \mathrm{Ar}$ ratio. Similarly, it is well known that if a small amount of nitrogen or hydrogen is injected in a pure He or Ar plasma, the electron energy is greatly consumed in the low levels of rotation and vibration of molecules implying significant changes of plasma properties (even with weak quantities). In the same manner, the electron energy is preferentially allocated to the lower excitation and ionization of Ar. This means that up to $80 \% \mathrm{He}$ the $\mathrm{Ar}^{+} / \mathrm{Ar}$ ratio increases with respect to $\% \mathrm{He}$ in the gas mixture since $\Phi_{\text {en, } 20 \% \text { Ar }}$ is only two times lower than $\Phi_{\text {en, } 100 \% \text { Ar instead of the }}$ expected five times. It seems this ratio increases by a factor of 2.5. Beyond $80 \% \mathrm{He}$ the depletion of Ar atoms means that more 
Table 2. Excitation and ionization energies of W, Ar and He.

\begin{tabular}{llll}
\hline & $\mathrm{W}$ & $\mathrm{Ar}$ & $\mathrm{He}$ \\
\hline Excitation energy (eV) & 3.41 & 13.1 & 23.0 \\
Ionization energy (eV) & 7.86 & 15.8 & 24.6 \\
\hline
\end{tabular}

electron energy is available to the excitation and ionization of He leading back to the expected drop of the sputtering rate.

Figure 12 reports both the absolute $\Phi_{\text {th }}$ and $\Phi_{\text {en }}$ on the same plot by using a semi-log scale as a function of the distance for 0,40 and $80 \% \mathrm{He}$. It can be observed that $\Phi_{\text {en }}$ strongly decreases while $\Phi_{\text {th }}$ grows slightly with the distance from the target. The drastic decrease of $\Phi_{\text {en }}$ is not the result of the thermalization process since only a small fraction of $\Phi_{\text {en }}$ loss passes to $\Phi_{\mathrm{th}}$. Indeed, between $z=0.8 \mathrm{~cm}$ and $z=3 \mathrm{~cm}$, $\Delta \Phi_{\mathrm{en}}=\Phi_{\mathrm{en}, 0.8 \mathrm{~cm}}-\Phi_{\mathrm{en}, 3 \mathrm{~cm}} \sim 1 \times 10^{15}$ atoms $\mathrm{cm}^{-2} \mathrm{~s}^{-1}$ while $\Delta \Phi_{\text {th }}=\Phi_{\text {th }, 3 \mathrm{~cm}}-\Phi_{\text {th }, 0.8 \mathrm{~cm}} \sim 5 \times 10^{13}$ atoms cm $\mathrm{cm}^{-2} \mathrm{~s}^{-1}$. To explain the behaviour of $\Phi_{\text {en }}$, one has to take into account the geometry of the energetic sputtered atoms' emission cone [22] as represented in figure 13. In fact, the further away from the target the probed volume is, the less likely it is to contain energetic $\mathrm{W}$ atoms since the section of the sputtered emission cone increases (figure 13: $S_{1}<S_{2}$ ). Considering the hypothesis of a distribution in cosine of the sputtered atoms, $50-65 \%$ of the sputtered vapour is globally emitted in a $\alpha=30^{\circ}-40^{\circ}$ emission cone with respect to the normal to the target surface [22]. The section at the basis of the cone is $\pi R_{0}^{2}$ with $R_{0}=1.3 \mathrm{~cm}$ being the racetrack radius, the section is equal to $\pi\left[R_{0}+z \cdot \tan (\alpha)\right]^{2}$ at distance $z$. In this range of $\alpha$, the ratio of sections between $z=3 \mathrm{~cm}$ and $z=0.8 \mathrm{~cm}$ is $S_{2,3 \mathrm{~cm}} / S_{1,0.8 \mathrm{~cm}} \sim 3-4$ which is in agreement with the ratio $\Phi_{\mathrm{en}, 0.8 \mathrm{~cm}} / \Phi_{\mathrm{en}, 3 \mathrm{~cm}} \sim 2-3$. This indicates once again that the measurements on the metastable level $5 d^{5}\left({ }^{6} \mathrm{~S}\right) 6 \mathrm{~s}$ seem to be representative of the $\mathrm{W}$ neutral ground state. However, the slight increase of $\Phi_{\text {th }}$ is the result of the conversion of a small part $(\sim 5 \%)$ of the energetic atoms flux into the thermalized one through elastic collisions with the buffer gas. Of course, the thermalization process depends on the Ar-He gas mixture.

The mean value of the ratio of sputtered $\mathrm{W}$ atom energies $E_{f} / E_{i}$ before $\left(E_{i}\right)$ and after $\left(E_{f}\right)$ elastic collision with the buffer gas is given by:

$$
\frac{E_{f}}{E_{i}}=1-\frac{2 M_{\mathrm{W}} M_{\mathrm{g}}}{\left(M_{\mathrm{W}}+M_{\mathrm{g}}\right)^{2}}
$$

where $M_{\mathrm{W}}$ is the atomic mass of $\mathrm{W}$ atoms and $M_{\mathrm{g}}$ is the atomic mass of the gas species. The ratio $E_{f} / E_{i}$ gives 0.71 for a W/Ar collision and 0.98 for a W/He collision. Consequently, W atoms need about 15 times more collisions to thermalize with He. The slower energy transfer in the collisional process than with Ar leads to a slower thermalization and better transport given by the increase of $\left\langle v_{z}\right\rangle$ with $\% \mathrm{He}$ (figure 14).

Note that the cathode voltage cannot explain this increase since it decreases. Even close to the target (at $z=0.8 \mathrm{~cm}$ ), the $\left\langle v_{z}\right\rangle$ increases slightly from $1900 \mathrm{~m} \mathrm{~s}^{-1}$ in pure Ar to $2200 \mathrm{~m}$ $\mathrm{s}^{-1}$ in $90 \% \mathrm{He}$. Note that the measured $\left\langle v_{z}\right\rangle$ agrees well with

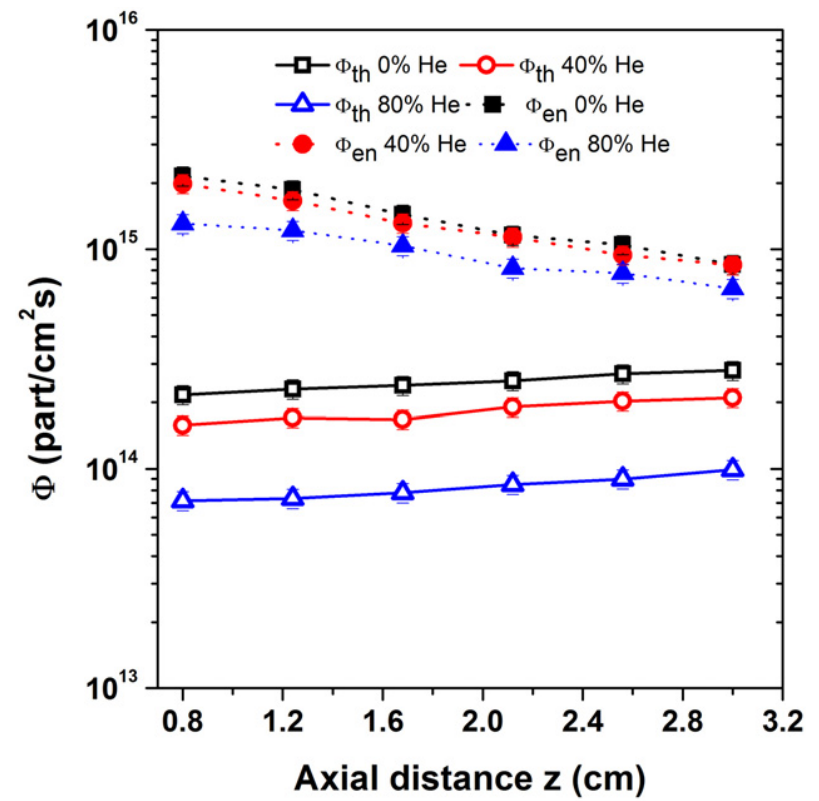

Figure 12. Axial evolution of $\Phi_{\text {en }}$ and $\Phi_{\text {th }}$. The measurements were performed at $R_{0}=1.3 \mathrm{~cm}$; pressure $=0.4 \mathrm{~Pa}$; magnetron power $=100 \mathrm{~W}$.

the literature [26]. One may notice that this slight increase of about $10 \%$ cannot be responsible for the discrepancy between $\Phi_{\text {en }}$ and the expected results (dashed line) in figure 11 which can rise up to $200 \%$. The slower energy transfer is also observed on the evolution of $\left\langle v_{z}\right\rangle$ with the distance to the target (figure 15). For $80 \% \mathrm{He},\left\langle v_{z}\right\rangle$ does not vary much with the distance indicating again limited energy transfers due to collisions during the transport. In accordance with the fact that the energy transfer is more efficient with the increase of Ar content, the measured $\left\langle v_{z}\right\rangle$ values decrease more rapidly with the distance $z$. In fact, $\mathrm{W}$ atoms with an initial velocity of about $1900 \mathrm{~m} \mathrm{~s}^{-1}(\sim 3.5 \mathrm{eV})$ thermalize (note that an atom is said to be thermalized when its velocity falls below three times the thermal speed which here is $\sim 260 \mathrm{~m} \mathrm{~s}^{-1}(\sim 0.04 \mathrm{eV})$ in a $500 \mathrm{~K}$ background gas [27]) after about 10 collisions in Ar gas and after about 100 collisions in He gas.

Using the previous conclusions, it becomes possible to give an interpretation of the observed behaviour of thermalized $[\mathrm{W}]_{\text {th }}$ atoms far from the target (figure $8, z=9 \mathrm{~cm}$ ). The $[\mathrm{W}]_{\text {th }}$ (similarly to the flux at this distance) and the deposition rate as functions of \% $\mathrm{He}$ exhibit a maximum at about 20 $40 \% \mathrm{He}$ instead of a proportional decrease (dashed lines). At first, the sputtering of $\mathrm{W}$ was expected to be in proportion to the gas mixture (as $Y_{\mathrm{Ar}} / Y_{\mathrm{He}} \approx 300$ ) which turned out to be an underestimate as the $\mathrm{Ar}^{+} / \mathrm{Ar}$ ratio increases up to $80 \% \mathrm{He}$. Moreover, the transport is enhanced with the increase of $\mathrm{He}$ content as the energy transfer during collisions is less efficient. This implies different properties of the sputtered vapour in terms of velocity and direction, i.e. atom flux is less isotropic leading to lower losses to the wall. Thus with the increase of $\% \mathrm{He}$, the lower sputtering of $\mathrm{W}$ possibly ends up being overcome by the improved transport and the increase of the $\mathrm{Ar}^{+} /$Ar ratio. 


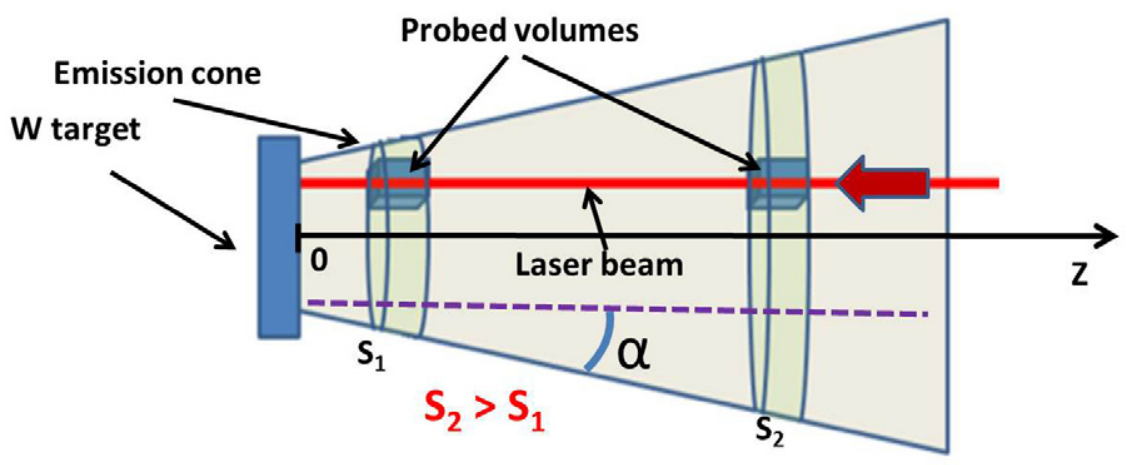

Figure 13. Scheme of the emission cone.

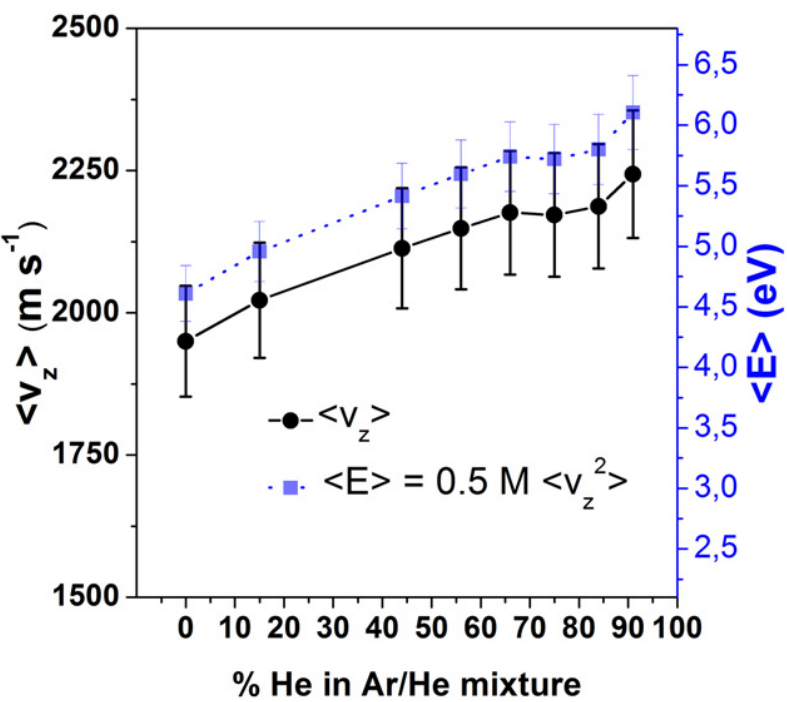

Figure 14. Mean velocity $\left\langle v_{z}\right\rangle$ and kinetic energy $\langle E\rangle$ of energetic $\mathrm{W}$ atoms as a function of the $\% \mathrm{He}$ in th $\mathrm{Ar}-\mathrm{He}$ gas mixture. The measurements were performed at $z=0.8 \mathrm{~cm}$ and $R_{0}=1.3 \mathrm{~cm}$; pressure $=0.4 \mathrm{~Pa}$; magnetron power $=100 \mathrm{~W}$.

\section{Conclusion}

This work consisted in the development of a method to perform original measurements on thermalized and energetic $\mathrm{W}$ atoms using tuneable laser-diode fluorescence (TD-LIF) and absorption (TD-LAS) spectroscopies. Those measurements were carried out in $\mathrm{Ar} / \mathrm{He} \mathrm{DC}$ magnetron plasmas. The atoms' velocity distribution function (AVDF), flux velocity distribution function (FVDF), density, flux as well as the mean velocity $\left\langle v_{z}\right\rangle$ of the energetic atoms were determined from the measured signals (TD-LAS and TD-LIF) by taking into account the particularities of $\mathrm{W}$ in the isotopes' hyperfine structure and resonance shifts for the resonance transition centred at $\lambda_{0}(\mathrm{~W})=407.4358 \mathrm{~nm}$. The TD-LIF calibration by TD-LAS allowed for the compensation of its main drawback (relative measurements). The TD-LIF data analysis highlighted that even at $z=3 \mathrm{~cm}$ the distribution of energetic $\mathrm{W}$ atoms has to be fitted with Stephanova et al's function [20]. Even though energetic W atoms undergo collisions with the buffer gas, due to the great difference in mass (with $\mathrm{Ar}$ and even more with $\mathrm{He}$ ), the energetic $\mathrm{W}$ atoms conserve a memory of the local information of the ejection (ejection

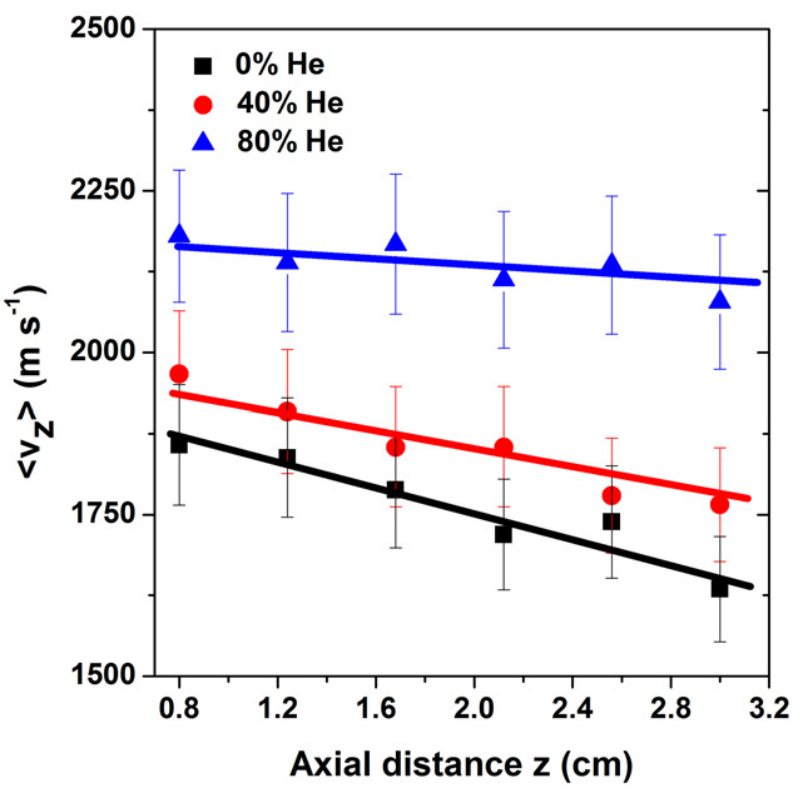

Figure 15. Axial evolution of the mean velocity $\left\langle v_{z}\right\rangle$ of energetic $\mathrm{W}$ atoms. The measurements were performed at $R_{0}=1.3 \mathrm{~cm}$; pressure $=0.4 \mathrm{~Pa}$; magnetron power $=100 \mathrm{~W}$.

angles and velocity distribution at the target surface $z=0$ ). The study showed that with the increase of the percentage of $\mathrm{He}$ in an Ar-He mixture, the expected lower sputtering is overcome by, on one hand, improved transport due to the poorer energy transfer implying different properties of the sputtered vapour in terms of velocity and direction and, on the other hand, an increase of the $\mathrm{Ar}^{+} / \mathrm{Ar}$ ratio leading to a significant sputtering yield and deposition rate even at $80 \% \mathrm{He}$. This was corroborated by measurements on the deposition rate exhibiting a maximum at $20 \% \mathrm{He}\left(2.8 \mu \mathrm{m} \mathrm{h}^{-1}\right)$ and a significant value at $80 \% \mathrm{He}\left(1.6 \mu \mathrm{m} \mathrm{h}^{-1}\right)$. This study reports absolute measurements, along the magnetron cathode axis, of AVDF, FVDF, density, flux as well as the mean energy of energetic atoms which can be of great interest both for fusion and deposition applications.

\section{References}

[1] Paturaud C, Farges G, Sainte Catherine M C and Machet J 1998 Influence of particle energies on the properties of 
magnetron sputtered tungsten films Surf. Coat. Technol. 98 1257-61

[2] Esteve J, Zambrano G, Rincon C, Martinez E, Galindo H and Prieto P 2000 Mechanical and tribological properties of tungsten carbide sputtered coatings Thin Solid Films $373282-6$

[3] Granqvist C G 2000 Electrochromic tungsten oxide films: review of progress 1993-1998 Sol. Energy Mater. Sol. Cells 60 201-62

[4] Vink T J, Walrave W, Daams J L C, Dirks A G, Somers M A J and Van den Aker K J A 1993 Stress, strain, and microstructure in thin tungsten films deposited by dc magnetron sputtering J. Appl. Phys. 74 988-95

[5] Roth J, Tsitrone E, Loarte A, Loarer T, Counsell G, Neu, R and Kukushkin A 2009 Recent analysis of key plasma wall interactions issues for ITER J. Nucl. Mater. 390 1-9

[6] Neu R, the ASDEX Upgrade Team, the EU PWI Taskforce and the JET EFDA Contributors 2011 Plasma Phys. Control. Fusion $\mathbf{5 3} 124040$

[7] Philipps V 2011 Tungsten as material for plasma-facing components in fusion devices J. Nucl. Mater. 415 S2-9

[8] Kallenbach A, Lang P T, Dux R, Fuchs C, Herrmann A, Meister, H and Zehetbauer T 2005 Integrated exhaust control with divertor parameter feedback and pellet ELM pacemaking in ASDEX Upgrade J. Nucl. Mater. 337 732-6

[9] Wolter M, Do H T, Steffen H and Hippler R 2005 Aluminium atom density and temperature in a dc magnetron discharge determined by means of blue diode laser absorption spectroscopy J. Phys. D: Appl. Phys. 382390

[10] Vitelaru C, Aniculaesei C, de Poucques L, Minea T M, Boisse-Laporte C, Bretagne J and Popa G 2010 Tunable diode-laser induced fluorescence on $\mathrm{Al}$ and $\mathrm{Ti}$ atoms in low pressure magnetron discharges J. Phys. D: Appl. Phys. 43124013

[11] Vitelaru C, de Poucques L, Minea, T M and Popa G 2011 Space-resolved velocity and flux distributions of sputtered Ti atoms in a planar circular magnetron discharge Plasma Sources Sci. Technol. 20045020

[12] Vitelaru C, de Poucques L, Minea T M and Popa G 2011 Time resolved metal line profile by near-ultraviolet tunable diode laser absorption spectroscopy J. Appl. Phys. 109053307

[13] De Poucques L, Imbert J C, Boisse-Laporte C, Bretagne J, Ganciu M, Teulé-Gay L and Touzeau M 2006 Study of the transport of titanium neutrals and ions in the post-discharge of a high power pulsed magnetron sputtering device Plasma Sources Sci. Technol. 15661

[14] De Poucques L, Vitelaru C, Minea T M, Bretagne J and Popa G 2008 On the anisotropy and thermalization of the metal sputtered atoms in a low-pressure magnetron discharge Europhys. Lett. 8215002

[15] De Poucques L, Imbert J C, Boisse-Laporte C, Vasina P, Bretagne J, Teulé-Gay L and Touzeau M 2005 Spatial characterization of an IPVD reactor: neutral gas temperature and interpretation of optical spectroscopy measurements Plasma Sources Sci. Technol. 14321

[16] Sushkov V, Do H T, Cada M, Hubicka Z and Hippler R 2013 Time-resolved tunable diode laser absorption spectroscopy of excited argon and ground-state titanium atoms in pulsed magnetron discharges Plasma Sources Sci. Technol. 22015002

[17] Britun N, Gaillard, M and Han J G 2008 Laser induced fluorescence for $\mathrm{Ti}$ and $\mathrm{Ti}+$ density characterization in a magnetron discharge J. Phys. D: Appl. Phys. 41185201

[18] Lee J, Chen J and Leanhardt A E 2013 High resolution isotope shifts and hyperfine structure measurements of tungsten by laser-induced fluorescence spectroscopy J. Phys. B: At. Mol. Opt. Phys. 46075003

[19] Thompson M W 1968 II. The energy spectrum of ejected atoms during the high energy sputtering of gold Phil. Mag. $18377-414$

[20] Stepanova M and Dew S K 2004 Anisotropic energies of sputtered atoms under oblique ion incidence Nucl. Instrum. Methods Phys. Res. B 21 357-65

[21] Kwon D H, Rhee Y J and Kim Y K 2006 Ionization of W and $\mathrm{W}^{+}$by electron impact Int. J. Mass Spectrom. 252 213-21

[22] Rossnagel S M, Cuomo J J and Westwood W D ed 1990 Handbook of Plasma Processing Technology: Fundamentals, Etching, Deposition, and Surface Interactions (Norwich, NY: William Andrew)

[23] Eckstein W, Stephens J A, Clark R E H, Davis J W, Haasz A A, Vietzke E and Hirooka Y 2001 Particle Induced Erosion of Be, $C$ and $W$ in Fusion Plasmas, Part B: Physical Sputtering and Radiation-Enhanced Sublimation (Atomic and Plasma-Material Interaction Data for Fusion vol 7) (Vienna: IAEA)

[24] Krishnakumar E and Srivastava S K 1988 Ionisation cross sections of rare-gas atoms by electron impact J. Phys. B: At. Mol. Opt. Phys. 211055

[25] Chapman B 1980 Glow Discharge Processes: Sputtering and Plasma Etching (New York: Wiley)

[26] Goehlich A, Niemöller N and Döbele H F 1999 Determination of angle resolved velocity distributions of sputtered tungsten atoms J. Nucl. Mater. 266 501-6

[27] Lu J and Lee C G 2012 Numerical estimates for energy of sputtered target atoms and reflected Ar neutrals in sputter processes Vacuum 86 1134-40 